\title{
Research on the Application of Modern Information Technology in the Practical Teaching of Computer Courses in Colleges and Universities
}

\author{
Yuan $\mathrm{Xie}^{1, *}$, Yuteng Zhang ${ }^{1}$, Shiqing Yao ${ }^{1}$, Junhong Liu ${ }^{1}$ and Suduo $\mathrm{Li}^{1,2}$ \\ ${ }^{1}$ College of Mathematics and Computer Science, Northwest University for Nationalities, Lanzhou, Gansu 730124, China \\ ${ }^{2}$ National Experimental Teaching Demonstration Center of National Information Technology, Northwest University for \\ Nationalities, Lanzhou, Gansu 730124, China \\ *Corresponding author. Email: xyuan011028@qq.com
}

\begin{abstract}
The introduction of modern information technology can catalyze the emergence of personalized-learning mode, improve teaching quality, strengthen the "freedom" of teachers, and fundamentally release students' initiative and activity. At present, the combination of computer courses practice teaching and modern information technology can improve the quality of teaching. However, there are many problems in the integration of the two, which affect the teaching effect. This paper takes the application of modern information technology in the practice teaching of computer courses in colleges and universities as the main content, introduces the important role of information technology in teaching practice, analyzes the application status of information technology in computer courses practice teaching combined with relevant data, and puts forward some optimized ideas pertinently. The main contribution of this paper is to construct a teaching mode of modern information technology that meets the current teaching needs. Finally, it optimized computer practice courses from the aspects of teachers, students, schools, and so on, providing new development ideas for computer teaching.
\end{abstract}

Keywords: modern information technology, Computer courses, Practical teaching, teaching reform

\section{INTRODUCTION}

The Outline of the National Medium-and Long-term Education Reform and Development Plan (2010-2020) takes improving quality as the core task of education reform and development, and establishes "the students-center" thought. Therefore, improving students' learning ability, thinking ability and practical ability is the key to current education[1]. With the continuous development of society, the importance of practical teaching is self-evident. It not only affects students' academic performance, but also relates to the trend of talent training in the future. Meanwhile, the sudden outbreak of COVID-19 in 2020 has created a huge challenge for education. In order to weaken the impact of the epidemic, the Ministry of Education has issued a series of notices, which mainly aimed at making full use of modern online teaching platforms to ensure the orderly progress of educational work during the epidemic prevention and control period. In addition, a variety of online learning platforms emerged under the impact of the epidemic. Online platform applications represented by Tencent Classroom, Dingding-meeting and Yu-classroom can minimize the negative impact of the epidemic. For computer practice courses, the learning mode with controllable progress and strong practicability can greatly improve the quality and efficiency of learning, showing that information technology plays a prominent role in teaching practice.

\section{ANALYSIS OF PRESENT SITUATION}

Here is modern information technology in the practical teaching of computer courses in colleges and universities.

\subsection{Teachers' Mastery and Application of Modern Information Technology}

At present, the combination of information technology and practical curriculum is the trend of future education development. Modern information technology has a variety of forms, not only the use of multimedia and PPT teaching, but also should include the skilled use of a variety of online teaching platforms, the development of auxiliary teaching websites, online homework correction, online tests and other new technologies. Taking full advantage of these technologies will enable the supervisors to better monitor students' learning states, effective realization one learns by teaching[2]. For example, teachers can make videos of the teaching content for students to learn by themselves in their spare time. There is no need to repeat the same content for each class in class. With time saved, teachers can move onto other more important things such as answering questions, 
correcting homework and realizing one-to-one tutoring, which are more conducive to the growth of students. However, as far as the current situation is concerned, it is very rare for teachers in public colleges to use software such as Whale-Card or QQ-group to correct homework, and they are not willing to collect software that can be used for online testing from the Internet. While teachers of some network training institutions are very skilled in the use of information technology, and use methods such as punching in homework, reviewing and supervising to realize the accompanying learning of students, which has better teaching effect.

\subsection{Students' Practical Learning Situation of Information Technology Courses}

The 21 st century is a society of higher information technology, students in this environment need to constantly adapt to modern information technology, and can flexibly apply advanced information technology, improve the ability to apply information, processing information, and then develop their practical ability[3]. Therefore, this paper conducted a questionnaire survey on students' application of information technology in practical courses, and collected 205 valid answers. The survey results are shown in Figure 1. According to the following survey results, students have a high degree of support for the introduction of information technology. There are $41 \%$ students expressed prefer the application of information technology in computer practice, and $32 \%$ students showed strong inclination for it. However, the actual learning situation is contrary to the results of the survey. First, because computer teaching content is often boring, students always hardly can concentrate on it. Secondly, the teaching content of computer courses is out of step with the actual social development. Teachers do not guide students through the introduction of teaching videos, resulting in the situation of "asking questions without answering", which affects the quality of students' learning in computer and becomes the "obstacle" hindering the reform of computer teaching.

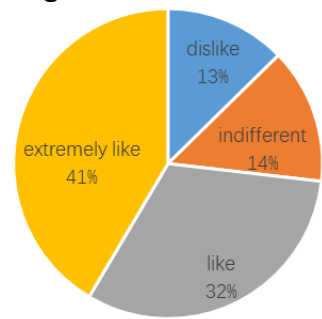

Figure 1. Students' expectation of using information technology in practical courses

\subsection{Basic situation of computer room that supports information technology courses}

As a practical course, computer courses have high requirements on the network environment of the computer room. Many works need to use the network such as distributing experimental data, sending materials, collecting class assignments, etc., especially in the process of debugging programs, students often need to search for the cause of failure and the countermeasures on the Internet. But in many cases, in order to prevent students from playing games online, schools often make rules to disconnect the Internet and only keep the internal network in computer rooms. Thus, brings some difficulties to teaching. If the course only involves sending and receiving homework or data, teachers can establish the FTP server or set up network neighbourhood to get it. However, without the Internet environment, it is more difficult for students to debug programs. When they encounter bugs, they have to rely on their mobile phones or go to places with Internet access after class to search for solutions, which delays the progress of the experiment and affects the learning effect. Therefore, it is necessary for teaching department to fully realize the importance of network and Information technology in computer practice courses and improve the management system of computer room.

\section{PROSPECT OF PRACTICE TEACHING OF COMPUTER COURSES}

\subsection{Innovate Teaching Methods and Establish Practical Consciousness}

The main purpose of practical teaching of computer courses is to concretize abstract theoretical knowledge and solve practical problems in reality through practical operation. Therefore, teachers should take deepening students' understanding as an end target firstly, adopting the differential teaching mode from the characteristics of students themselves[4]. At the same time, strengthen the ability of computer practice operation, so that students in the study of computer practice courses will be the combination of theory and practice, enhance the interest in the application of information technology, fully arouse the enthusiasm of students. Secondly, teachers can introduce diversified evaluation models and use rationalization strategies when evaluating students' homework. Take encouragement as the main force and criticism the auxiliary force. In this way, students can not only discover the problems existing in practice, but also understand the advantages shown in the process of practice, so as to promote the formation of a more ideal reflection role, which is conducive to subsequent improvement and adjustment. Thirdly, open the teaching mode of the combination of online and offline. There is some difference between online practice teaching and offline teaching. Online teaching requires teachers to prepare the content of students' practice in advance and make simple design for online practice. The combination of modern information technology and computer practice teaching has become a development trend of The Times. Therefore, only by taking the express of The Times, 
innovating the teaching consciousness and changing the teaching mode can we improve the teaching quality.

\subsection{Master Learning Strategies and Avoid Laziness}

Under the background of continuous development of network information technology, students' knowledge acquisition of computer practice courses is not only important for daily teaching, but also for self-practice and self-improvement. Firstly, students should master ideal learning strategies to drive the application of information technology. For difficult learning tasks, the group mode can be used, which can not only improve the efficiency of problem solving, but also fundamentally strengthen students' cooperation ability. In this group-learning mode, students can also develop various qualities and abilities, which should become an important means of learning for future students. Secondly, strengthen the ability of independent learning. Based on the actual situation, we can understand the reasons why students like online learning. On the one hand, they can study independently and on the other hand, they can keep in touch with teachers after class. If they have any questions, they can ask teachers online. In addition, hierarchical teaching tasks help improve computer practice level. Compared with the previous classroom-teaching model, the application of modern information technology needs to pay more energy, such as preparing high-quality course resources and answering students' questions online. Finally, we should pay more attention to information technology. According to the above survey, most students are aware of the importance of modern information technology in practical learning, but it is often ignored in practice. Therefore, students can upload homework independently to ensure that information technology runs through computer practice courses. General websites can be developed to provide relevant documents for experiments and promote the better application of "Internet $+"$ and other new teaching modes.

\subsection{Update the Network Equipment and Optimize the Course System}

First, we need to deepen the coverage of online learning space, promote the implementation of the "Guidance of the Ministry of Education on Strengthening the Construction and Application of E-Learning Space "and" Guide to the Construction and Application of Online Learning Space ", and accelerate the popularization and application of online learning space across the country[5]. Second, reorganize teaching material of computer practice. At present, the content of computer practice textbooks in some colleges can no longer meet the increasing needs of students, so schools should pay more attention to the construction of computer practical teaching materials and optimize their contents. Modifying the new textbook contents should insist on the idea of "student-centered", making a deeper understanding of the structure of the computer teaching material and its future trend. In this way to adjust and enrich the teaching material, and increase computer practice content properly[6]. Third, we need to carry out targeted intelligence support in cyberspace. We have worked out the guidelines on strengthening the application of the "Three Classrooms," vigorously promoted the model of "high-quality schools supporting weak schools, and excellent teachers supporting ordinary teachers," and helped schools in remote and poor areas lacking qualified teachers improve their teaching quality by using information technology tools[7].

\section{CONCLUSION}

According to the 13th Five-Year Plan for the Development of National Education: Teachers are encouraged to use information technology to improve their teaching level, innovate teaching models, and make good use of highquality digital resources such as flipped classroom and mixed teaching model. Thus, it can be seen that with the continuous development of network information today, the reform of education is closely linked to information technology. Teaching individuation and independence also become the trend of current education development. Based on the model of "Internet +", this paper aims to optimize the computer practice curriculum from the aspects of teachers, students and schools, providing new development ideas for the current computer teaching. From the perspective of computer and information technology convergence, this new type of teaching mode is not only the opportunity in the process of teaching reform, but also a great challenge for schools and teachers. So, teachers have to constantly improve their own literacy, strengthen the cognition of information technology. Only then can it be applied flexibly in concrete practice teaching, weakening the influence of external factors such as the epidemic, and guaranteeing teaching quality fundamentally.

\section{ACKNOWLEDGMENT}

This work is supported by: Laboratory Open Project of Northwest University for Nationalities in 2021(No. SYSKF2021176); General project of education and Teaching Reform research of Northwest University for Nationalities in 2021; Innovation and Entrepreneurship Training program for college students of Northwest University for Nationalities.

\section{REFERENCES}

[1] Yang Weiyan. Exploration and practice of mobile learning mode in computer courses in secondary vocational schools [J]. Information and computer (theoretical Edition), 2019, 31 (18): 252-254

[2] Yin Jie, Song Siqi. Research on practical teaching of information technology application of urban and rural planning specialty under the background of "digital 
transformation" [J]. Journal of higher education, 2019 (08): 91-93

[3] Xie Haiying, Zhao Jiaojie. Research on practical teaching mode of computer courses based on "Mu class + project driven" [J]. Information and computer (theoretical Edition), 2018 (21): 218-220

[4] Shang Liang. A preliminary study on the teaching reform of Optoelectronic Information Courses Based on computer simulation technology [J]. China modern educational equipment, 2018 (11): 39-41
[5] Jiang Shuhao, Wang Guirong, Su Xiaoqin. College Computer Practice Course [M]. People's Posts and Telecommunications Press, 201708.173

[6] Wang Xiaoli. College Teachers' computer selfefficacy and teaching mode reform of economic courses in the development of information technology [J].

Introduction to scientific and technological innovation, 2014.11 (20): 112-113

[7] Xing Yuanxiu, Yin Shuifang, YU Shengchun. Exploration on practical teaching of Computer courses for Information and Computing majors [J]. University Education, 2013(15):115-116. 